\title{
ROBÓTICA EDUCACIONAL COMO FERRAMENTA MEDIADORA: ABORDANDO CONCEITOS MATEMÁTICOS NA FORMAÇÃO DE PROFESSORES
}

\author{
EDUCATIONAL ROBOTICS AS A MEDIATING TOOL: \\ ADRESSING MATHEMATICAL CONCEPTS IN TEACHER \\ TRAINING
}

\begin{abstract}
ROBÓTICA EDUCATIVA COMO HERRAMIENTA MEDIADORA: ABORDAR CONCEPTOS MATEMÁTICOS EN FORMACIÓN DEL PROFESORADO
\end{abstract}

Zaira Karine Almeida Batalha Rodrigues ${ }^{1}$ (D) 0

José Ricardo e Souza Mafra ${ }^{2}$ (D) 9

\begin{abstract}
RESUMO
Este artigo apresenta uma investigação sobre a robótica e a sua utilização metodológica como alternativa no desenvolvimento das aprendizagens, através da compreensão teórica e prática de sua possível incorporação no ambiente educacional. Deste modo, objetivou-se desenvolver um cenário educacional para a robótica, a partir da concepção de uma espécie de ferramenta mediadora do conhecimento, capaz de contribuir para aprendizagens educacionais. Os encaminhamentos metodológicos desenvolvidos tiveram como base pressupostos de uma pesquisa com características de uma abordagem participante, de cunho exploratório. As etapas metodológicas envolveram o desenvolvimento e planejamento de atividades tecnológicas, articuladas a uma proposta extensionista, tendo como público-alvo professores em formação inicial. Os resultados apresentados - tanto através das nossas observações, como dos participantes da pesquisa, através de um questionário avaliativo - forneceram elementos para se pensar nessa metodologia tecnológica como uma potencial mediadora de conhecimentos, atuando em formato de estratégia pedagógica alternativa para novos paradigmas metodológicos, com base na educação e suas interfaces para com as tecnologias educacionais.
\end{abstract}

Palavras-chave: Ensino. Formação continuada. Robótica Educacional. Ferramenta mediadora. Extensão.

\begin{abstract}
This article presents an investigation about robotics and its methodological use as an alternative in the development of learning, through theoretical and practical understanding of its possible incorporation in the educational environment. Thus, the aim was to develop an educational scenario for robotics, based on the conception of a kind of knowledge mediating tool, capable of contributing to educational learning. We based the methodological guidelines developed on the assumptions of an investigation with

\footnotetext{
${ }^{1}$ Graduação em Licenciatura em Informática Educacional pela Universidade Federal do Oeste do Pará (UFOPA). Pesquisadora independente, Santarém, Pará, Brasil. Endereço para correspondência: Av. Marechal Rondon, s/n, Bairro Caranazal, Santarém, Pará, Brasil, CEP 68040-070. E-mail: zaira.batalha@gmail.com.

${ }^{2}$ Doutorado em Educação pela Universidade Federal do Rio Grande do Norte (UFRN). Professor permanente do Programa de Doutorado em Educação em Ciências e Matemática (PPGECEM) - Associação em Rede - intitulada Rede Amazônica de Educação em Ciências e Matemática (REAMEC) e do Programa de Pós-graduação em Educação - PPGE/UFOPA, Santarém, Pará, Brasil. Endereço para correspondência: Av. Marechal Rondon, s/n, Bairro Caranazal, Santarém, Pará, Brasil, CEP 68040-070. E-mail: jose.mafra@ufopa.edu.br.
} 
characteristics of a participatory approach, of an exploratory nature. The methodological steps involved the development and planning of technological activities, linked to an extension proposal, with the target audience of teachers in initial training. The results presented - both through our observations and those of the research participants, through an evaluative questionnaire - provided elements to think about this technological method as a potential mediator of knowledge, acting as an alternative pedagogical strategy for new methodological paradigms, based on in education and its interfaces with educational technologies.

Keywords: Teaching. Continuing educacion. Educational Robotics. Mediating tool. Extension.

\section{RESUMEN}

Este artículo presenta una investigación sobre la robótica y su uso metodológico como alternativa en el desarrollo del aprendizaje, a través de la comprensión teórica y práctica de su posible incorporación en el ámbito educativo. De esta manera, el objetivo fue desarrollar un escenario educativo para la robótica, basado en la concepción de una especie de herramienta mediadora del conocimiento, capaz de contribuir al aprendizaje educativo. Los lineamientos metodológicos desarrollados se basaron en los supuestos de una investigación con características de enfoque participativo, de carácter exploratorio. Los pasos metodológicos involucraron el desarrollo y planificación de actividades tecnológicas, vinculadas a una propuesta de extensión, con el público objetivo de docentes en formación inicial. Los resultados presentados, tanto a través de nuestras observaciones como por los participantes de la investigación, a través de un cuestionario evaluativo, proporcionaron elementos para pensar en esta metodología tecnológica como un potencial mediador del conocimiento, actuando en forma de una estrategia pedagógica alternativa para nuevos paradigmas metodológicos, basados en la educación y sus interfaces con las tecnologías educativas.

Palabras clave: Enseñando. Educación continua. Robótica Educativa. Herramienta mediadora. Extensión.

\section{INTRODUÇÃO}

O desenvolvimento da humanidade, concentrou-se conscientemente na ciência e principalmente na tecnologia, tendo-os como alguns dos principais pontos de partida para o crescimento, evolução e distribuição de conhecimentos em suas diversas áreas, gerando transformações de espaço e tempo, marcadas pelos avanços sociais.

A partir desta perspectiva, destacou-se duas grandes vertentes transformadoras, a primeira sendo a Educação, como "uma das atividades humanas com maior responsabilidade pelo desenvolvimento de uma Nação, em todos os seus aspectos" (SANTANA, 2009, p. 21) e presente no cotidiano da humanidade desde seus primórdios, tornamo-nos capazes de adquirir, absorver e transmitir conhecimentos das mais diversas formas possíveis. A segunda vertente, diz respeito a Tecnologia Digital - definição assumida neste trabalho, através das Novas Tecnologias - enquanto "produtos sociais, modificam nossas maneiras de pensar, sentir e agir, nossas formas de comunicação, nossas maneiras de nos relacionarmos e os processos de ensino 
e aprendizagem" (ARAUJO, 2015, p. 46). Desse modo, envolve pessoas, máquinas, ferramentas, software e hardware, entre outras possibilidades, em uma grande rede de informações e comunicações intelectuais, como explicitado por Araújo (2015).

Assim, trabalhando como fontes de possibilidades e conhecimentos, a Educação e a Tecnologia Digital tornam-se grandes protagonistas no século XXI, presentes na maioria das atividades realizadas no cotidiano de diversos grupos sociais.

Neste sentido, este estudo pretende ressaltar uma, dentre as possibilidades resultantes da relação direta entre a Educação e a Tecnologia Digital: a Robótica Educacional, que, como citada por Galvão (2018, p.10) "é uma ferramenta de universo abrangente e diretamente conectada com as tecnologias de informação e comunicação".

Proveniente da Robótica fundamental, a Robótica Educacional (RE) surge como uma ferramenta útil, proveitosa e que pode ser empregada de diferentes formas como uma fonte alternativa de obtenção e transmissão de informações e aprendizados - como um instrumento de aprendizagem moderna, imprescindível para a inserção educacional de assuntos abordados, desde a Educação Infantil, perpassando pelas duas etapas do Ensino Fundamental e do Ensino Médio, até chegar a Educação Superior.

Com isso, faz-se necessário compreender a RE como ferramenta impulsionadora da educação tecnológica, nas salas de aula, como um instrumento capaz de ser utilizado em diversas aplicações envolvendo disciplinas específicas, como a matemática, por exemplo, projetando assim, um possível método pedagógico ou modelo de imersão do estudante no ensino.

Atuando, portanto, como uma forma alternativa e subsidiária de aprendizado aos olhos dos alunos e nas mãos dos professores, a RE deve ser administrada corretamente dentro e fora da sala de aula, de modo que culmine em aprendizado. Assim, tanto para os estudantes, quanto para o professor - principal responsável por possibilitar esta metodologia alternativa de ensino em suas aulas - ela visa fortalecer o ensino e proporcionar também conforto e ludicidade através da educação, com um intuito de projetar um diferencial importante no processo de aquisição de conhecimentos e conceitos educacionais.

Com base nessas considerações iniciais, objetivou-se responder a seguinte questão: como a Robótica Educacional pode contribuir, através de propostas e situações educacionais em sala de aula, no processo de professores em formação? 
Assim, objetivou-se desenvolver nesta investigação, a produção de um cenário educacional para a robótica, a partir da concepção de uma espécie de ferramenta mediadora do conhecimento, capaz de contribuir para aprendizagens educacionais.

Nesse sentido o questionamento proposto e o objetivo associado ao mesmo, foram pensados em uma perspectiva de se projetar e organizar cenários metodológicos e tecnológicos alternativos para o ensino, de forma que seja possível elencar movimentos e dinâmicas educacionais, em ambientes diversos e que sejam capazes de contribuir para os processos formativos de professores.

Consequentemente, o que se espera é que essa contribuição seja refletida em aprendizado e conhecimento de qualidade para nossos estudantes, especialmente os estudantes que possuem dificuldades para a aprendizagem de conceitos matemáticos. Dado que, as atividades que serão apresentadas neste estudo, convergem para a possibilidade de visualização de cenários educacionais envolvendo as aprendizagens matemáticas. Assim, este estudo apresenta elementos para se pensar também a questão da formação docente e o ensino de matemática, já que apresenta um relato de experiência nesse sentido, o qual pode se configurar em uma proposta alternativa e viável para o ensino de conceitos matemáticos.

\section{REFERENCIAL TEÓRICO}

Em busca de pontos norteadores para esta pesquisa, realizou-se um levantamento bibliográfico, assim como uma revisão de literatura sobre a Robótica Educacional e estudos adjacentes, em diferentes bases de dados e plataformas de pesquisa na Internet, tais como: $\underline{\text { Google Acadêmico, }}{ }^{3} \underline{\text { Scielo }}^{4}$ e Periódicos da $\underline{\text { Capes. }}^{5}$ As palavras-chave utilizadas para este levantamento e revisão foram: robótica e robótica educacional. Neste sentido, foram selecionados textos norteadores acerca da utilização da robótica educacional na educação matemática, listados a seguir: Aciolli (2005), Santana (2009), César (2009), Moraes (2010) e Barbosa (2016).

Também foram consultados, para este trabalho, textos e dissertações (ARAÚJO, 2015; ARAÚJO e MAFRA, 2015; GALVÃO, 2018), tendo como recorte principal de recuperação de

3 Plataforma de pesquisa do Google, que torna possível a pesquisa através de artigos acadêmicos, livros escolares,
jornais universitários etc. Para mais informaçoses acesse o site: $h$ ttps://scholar. google.com.br
4 Biblioteca Eletrônica Científica Digital de periódicos científicos que permite a publicação digital e livre acesso
de trabalhos brasileiros e de outros países. Para mais informações acesse o site: $\underline{h t t p s: / / s c i e l o . o r g}$
5 Plataforma de acesso a artigos acadêmicos e outras categorias de periódicos científicos criado pela CAPES em
2011. Para mais informações acesse o site: https://www.periodicos.capes.gov.br 
dados, estudos relacionados a robótica educacional e que projetavam experiências e vivências dentro e fora da sala de aula, para fins educativos (BARBOSA et al. 2018).

O trabalho de Aciolli (2005) instiga sobre as funcionalidades e potencialidades do ambiente robótico de aprendizagem, com alunos do ensino fundamental, nas turmas de $3 .^{\circ}, 4 .^{\circ}$, 5. e 7. ano, utilizando o robô como um "dançarino" que responde aos comandos através das configurações realizadas. Santana (2009), fornece uma discussão sobre a Robótica pedagógica (termo usado pela autora), ou Robótica Educacional, como uma das possibilidades buscadas no título de sua tese, realizada com alunos do $4 .^{\circ}$ ano de uma escola da rede pública de ensino, enquanto, o trabalho desenvolvido por César (2009), apresenta uma discussão sobre o processo de (re)construção de conceitos científico-tecnológicos, com base no desenvolvimento de artefatos robóticos, analisando o uso de softwares e hardwares livres na construção e reconstrução de conceitos tecnológicos, através da produção de kits de robótica pedagógica livres.

A pesquisa desenvolvida por Moraes (2010), projeta um instrumento de desenvolvimento e envolvimento da aprendizagem de cunho matemático, com o objetivo de investigar o uso da robótica em alunos do $8 .^{\circ}$ ano, utilizando os seguintes robôs: balança de dois pratos, robô girafa e ponte levadiça, explorando e problematizando através da Robótica Educacional e da Matemática. Araújo (2015), disserta sobre as potencialidades pedagógicas evidenciadas através da Teoria da Atividade, isto posto, com alunos do 9. ${ }^{\circ}$ ano do ensino fundamental de uma escola da rede pública de ensino, na cidade de Santarém/PA.

Araújo e Mafra (2015), explanam sobre a "Robótica Educacional" como um artefato a ser empregado em ambientes, numa perspectiva de Aprendizagem Colaborativa que, em nosso entendimento, trata-se de uma situação na qual dois a cinco indivíduos aprendem ou tentam aprender algo juntos (DILLENBOURG, 1999), conforme citado por Araújo \& Mafra (2015). Estas características também objetivam agregar a capacitação e o desenvolvimento do trabalho colaborativo em ambientes, como a sala de aula, por exemplo, garantindo, em tese, um seguro processo de aprendizagem.

Barbosa (2016), buscou através de sua pesquisa sintetizar sobre a relação do jovem com o estímulo da tecnologia na educação, através de uma proposta educacional realizada a partir do Subprojeto de Matemática do Programa Institucional de Bolsa de Iniciação à Docência (PIBID), tendo como público-alvo estudantes do ensino médio de uma escola pública, na cidade de Uberlândia em Minas Gerais. 
Galvão (2018), disserta sobre sua proposta de ensino, na disciplina de matemática em uma escola pública da cidade de Santarém, no Pará, com alunos do ensino fundamental. O autor relata sobre a experiência no laboratório de informática da escola e da participação dos alunos com esta nova perspectiva de aprendizado, a qual, de acordo com as suas conclusões, contribuem para o interesse e a motivação dos estudantes em suas aprendizagens.

Em relação à formação docente, com o propósito de subsidiar nossas discussões, os estudos de Cardoso (2016), Fantin (2017) e Avelar, Silva e Nascimento (2019) fornecem elementos estruturantes e complementares para a escrita desta pesquisa, subsidiando a formação inicial de acadêmicos e a inserção das tecnologias digitais em seu contexto educacional. O estudo de Cardoso (2016), por exemplo, discorre sobre a formação inicial de professores, utilizando as experiências de licenciandos de Letras Português-Inglês no estágio docente, o importante papel do professor orientador e o preparo no manuseio de tecnologias digitais durante a graduação, culminando no reforço de uma formação continuada de estagiários, para o uso da tecnologia em ambientes educacionais, objetivando enriquecer o ensino-aprendizado.

Fantin (2017), desenvolveu uma pesquisa colaborativa, cujo principal objetivo foi mostrar a validade em compreendermos interfaces em meio a educação, aprendizagem e tecnologias, entre professores, estudantes e pesquisadores, sob uma perspectiva da pesquisaação. Seu estudo discute sob o prisma do desafio contemporâneo da inserção das tecnologias digitais no ambiente educacional e o impacto da cultura digital na formação acadêmica, formação continuada de professores e contextos socioculturais.

Estudos como os informados anteriormente, mostram o quanto a proposta de implementação da robótica, na educação tem como objetivo básico, o enriquecimento de conhecimentos e transformação do ambiente clássico da sala de aula. Ao se falar em ambientes alternativos, tais como um laboratório de aplicações tecnológicas ou um laboratório de informática, por exemplo, estamos pressupondo cenários e configurações de ensino e de aprendizagem, cujo componente de inovação e criatividade possam ser implementados e potencializados, com sucesso. Assim, é necessário reconhecer, através de diferentes experiências de ensino, que a utilização desta metodologia inovadora - doravante, denominada ferramenta mediadora do conhecimento - foi pensada como uma tecnologia capaz de auxiliar e fortalecer o trabalho desenvolvido pelo professor e que pode fornecer benefícios para a prática diária em sala de aula, de forma a contribuir para o aprendizado e conhecimento, como alternativa possível no ambiente escolar. 
A RE como ferramenta mediadora de conhecimento, pode ser pensada, nos termos de Araújo (2015), como um aspecto em que se discute que, "desde muito tempo o Homem busca projetar e construir artefatos (robôs) que imitem ações humanas e/ou o substitua" (p. 58). Do ponto de vista educacional, este "artefato" pode se configurar como uma ferramenta de auxílio, promovendo o aprofundamento do conteúdo ministrado pelo docente.

Em contraste, Barbosa et al. (2018, p. 1), discursa sobre a prática da robótica educacional como uma "ferramenta mediadora de ensino-aprendizagem da matemática no ensino fundamental", de forma a promover atividades capazes de impulsionar uma melhor compreensão, além de estimular o interesse expressivo dos discentes em aprender por métodos diferenciados.

Para Barbosa et al. (2018, p. 2):

A utilização da robótica tem possibilitado melhorias no processo educativo, tanto em conteúdos técnicos voltados a programação, como no aproveitamento de outras disciplinas como a matemática, podendo estimular a capacidade de elaborar hipóteses, estabelecer relações e descobrir novos caminhos na aplicação de conceitos adquiridos teoricamente.

Avelar, Silva e Nascimento (2019), dissertam sobre as políticas municipais acerca da realidade da inserção do profissional educacional no mercado de trabalho, ressaltando sobre a formação continuada como estímulo para o aprimoramento do uso das tecnologias em atuação na sala de aula. Assim, podemos perceber também uma amplitude de trabalhos e propostas relacionais envolvendo as tecnologias e suas relações com aspectos formativos e de uso em sala de aula, para além da RE. Um bom exemplo desta amplitude pode-se verificar no trabalho de Santos, Silva e Rosa (2020), ao desenvolverem atividades lúdicas e experimentais, com base na utilização de simuladores e, também, na pesquisa realizada por Jacon et al. (2013), ao apresentarem possibilidades e ações relacionadas ao uso dos dispositivos móveis, em ambientes educacionais.

\section{METODOLOGIA}

Os pressupostos informados anteriormente, apresentam subsídios para pensar em iniciativas - tal como a proposta neste trabalho - como um instrumento metodológico de ensino válido, nas ações de apropriação de conhecimentos, tanto por parte dos professores (com vistas 
ao seu processo formativo) como dos próprios alunos (aplicações em sala de aula, destes conhecimentos adquiridos, ao longo deste processo formativo).

Os encaminhamentos metodológicos foram desenvolvidos, com base em uma perspectiva de um estudo exploratório, seguindo uma linha de abordagem com elementos característicos de uma pesquisa qualitativa, do tipo participante (GIL, 1999). Nesse sentido, objetivou-se delinear um cenário de investigação, a partir de um conjunto de atividades, com características do tipo experimento, tendo como finalidade básica o fornecimento de subsídios de respostas para este estudo, através da organização e efetivação de informações, através de etapas, descritas a seguir.

Na etapa inicial da investigação foi realizado uma pesquisa bibliográfica, em busca de fontes e referenciais que estivessem relacionados com este objeto de estudo (LAVILLE e DIONE, 1999). Seguiu-se uma etapa de planejamento e desenvolvimento de material tecnológico, com base na robótica educacional, de forma a dimensionar uma sequência de atividades educacionais, voltadas para a compreensão conceitual de objetos de caráter matemático. Na sequência, realizou-se um minicurso de extensão, tendo como público-alvo professores em formação inicial, de forma a testar e validar as atividades desenvolvidas. A validação e análise dos resultados deste estudo também foi reforçada com a aplicação de um questionário, ao final das atividades, de forma a obter informações dos participantes sobre os resultados alcançados e processos desenvolvidos, relativos à robótica educacional e aos propósitos desta pesquisa.

Os critérios de análise assumidos foram delineados em função das inferências realizadas das observações, quando da ocorrência do minicurso de extensão proposto, produção de registros e situações de ensino apresentadas pelos alunos, durante o desenvolvimento das atividades. Além disso, as informações geradas, em função da aplicação dos questionários ao final das atividades, permitiram a abstração de representações e de esquemas conceituais informados, para os propósitos deste estudo, quando da resolução e discussão das atividades apresentadas. Assim, com base nos estudos de May (2004) e Minayo (2001), realizou-se uma conexão destas impressões (registros) com os referenciais teóricos e pesquisas associadas a este estudo, informados na seção anterior, de forma a correlacionar as informações obtidas com os objetivos e proposições apresentadas neste artigo.

Partindo destes pressupostos, a RE atuou como base para o dimensionamento metodológico desta pesquisa, associada a uma atividade de extensão, originalmente direcionada para acadêmicos dos cursos de Licenciatura em Informática Educacional (LIE) e Licenciatura 
Integrada em Matemática e Física (LIMF), vinculados a Universidade Federal do Oeste do Pará (UFOPA).

Assim, assumimos que a integração entre a robótica educacional, como uma ferramenta mediadora do conhecimento, no ambiente de ensino, oportunizaria uma relação de qualidade de trabalho a ser desenvolvido, com os participantes da pesquisa, através das atividades propostas e explorações a serem realizadas, quando da promoção da ação de extensão.

Para o desenvolvimento desta atividade de extensão, ela foi devidamente cadastrada na Pró-reitoria da Cultura, Comunidade e Extensão (PROCCE) da UFOPA, como atividade de extensão do Grupo de Ensino e Pesquisa em Educação, Matemática e Interdisciplinaridade na Amazônia (GEPEIMAZ). Os instrumentos de trabalho utilizados nesta proposta foram os Kits de robótica LEGO $^{6}$ Mindstorms Education ${ }^{\circledR 7}$, a partir do qual foi efetuado um estudo instrumental inicial de reconhecimento e planejamento educacional, para realizar as ações previstas com os participantes. Em adição, a compreensão e domínio do programa EV3 permitiu um entendimento da programação básica de robôs, de forma a projetar e idealizar determinadas tarefas, com um foco educacional, aos instrumentos robotizados.

A programação dos robôs foi gradualmente introduzida, durante o desenvolvimento do planejamento das atividades, de forma a fornecer a equipe de trabalho - composta pelo professor orientador e duas acadêmicas do Curso de LIE, da turma de 2016 -, subsídios para a aquisição de habilidades com a programação e ideias de aplicação para a RE, na área de conhecimento escolhida, como suporte conceitual para as ações projetadas, neste caso, a matemática.

Em seguida, ficou definido que as atividades ocorreriam em duas etapas, sendo elas: reconhecimento dos componentes dos robôs e a programação/implementação de formas geométricas através Lego Mindstorms Education ${ }^{\circledR}$ e o programa EV3 ${ }^{\circledR}$ de modo a cada um representar e elaborar, com o auxílio dos dispositivos tecnológicos disponíveis, uma forma geométrica diferente. Nesse sentido, a perspectiva de atividade prevista, visando uma possível situação proposta para o ensino de matemática, foi desenvolvida, com base no reconhecimento de formas (figuras geométricas) escolhidas e a capacidade de programação associada à configuração delas, a saber: círculo, quadrado, retângulo, triângulo e losango.

\footnotetext{
6 "LEGO": leg godt que significa "brincar bem"

7 O LEGO ${ }^{\circledR}$ MINDSTORMS ${ }^{\circledR}$ Education EV3 é uma solução de robótica educacional, que estimula o Aprendizado de STEM (sigla internacional para as áreas de Ciências, Tecnologia, Engenharia e Matemática). Mais informações em https://tecnologia.educacional.com.br/blog-robotica-e-stem/o-que-e-lego-mindstorm-education$\underline{\text { ev3/ }}$
} 
Para demonstrar melhor preparação durante a execução das atividades previstas, foram feitas programações aplicáveis a cada forma geométrica. Os robôs foram previamente preparados, montados e programados para o primeiro contato com os participantes da pesquisa, tendo em vista que existia a possibilidade de nem todos possuírem conhecimentos prévios com a RE em sala de aula.

A programação dos robôs foi aos poucos introduzida, durante o desenvolvimento do planejamento das atividades, de forma a fornecer a equipe de trabalho, subsídios para a aquisição de habilidades com a programação e ideias de aplicação para a Robótica Educacional, na disciplina de matemática, tal como a Figura 1 apresenta, ao representar a programação associada à configuração dos ângulos internos e opostos ao ângulo de $90^{\circ} \mathrm{em}$ um triângulo retângulo, do tipo isósceles.

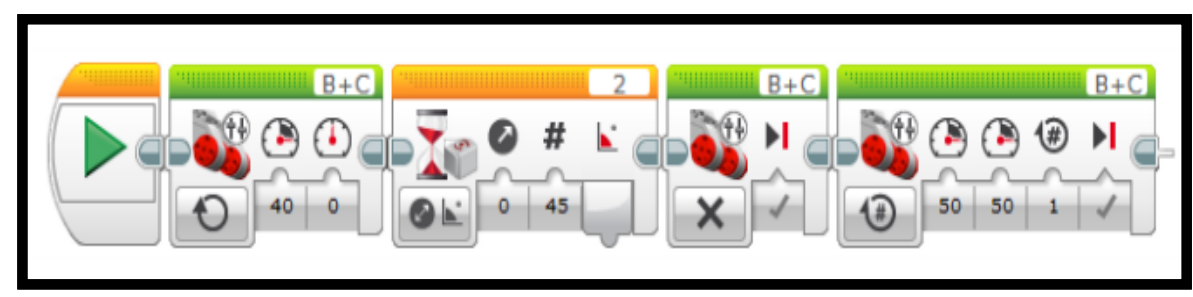

Figura 1 - Programação de Ângulo de 45 graus Fonte: Produção do autor (2019)

Abordar um conteúdo tão específico como "as formas geométricas” pode parecer fácil para professores em formação, porém, não é tão simples assim. Desde que é proposta uma atividade através da programação das formas geométricas pelos robôs LEGO, o que parecia simples, tornou-se diferenciado e desafiador, para os pesquisadores e participantes, exatamente por ser um dos principais objetivos da RE: a inovação na abordagem do conteúdo.

Assim, quando da operacionalização das atividades, foram realizados procedimentos e experimentos visando a discussão de possibilidades: movimentação e percursos dos robôs já montados e programados, percursos e trajetos, o atrito das rodas do robô com o chão ou qualquer outro lugar que pudessem ser alocados, consequências e interferências (obstáculos) na execução das atividades pré-programadas.

Deste modo, o minicurso intitulado "Robótica Educacional: uma proposta de aprendizagem", foi desenvolvido como um instrumento estratégico e integrador - para os propósitos desta pesquisa - haja vista que realizamos uma ação de formação articulada com os propósitos relacionados à extensão universitária. Antes do início das atividades, foi distribuído 
aos participantes, um TCLE (termo de consentimento livre e esclarecido) para o correto uso posterior de informações, imagens e ideias colhidas durante o minicurso aplicado.

O minicurso contou com a participação de 27 professores em formação no primeiro dia e 24 no segundo: acadêmicos de diversos cursos da Universidade Federal do Oeste do Pará (UFOPA) e de outras instituições como a Escola de Ensino Técnico do Pará (EETEPA) e Instituto Federal do Pará (IFPA), participaram. O perfil de idade associado às participações de homens e mulheres, foi entre 18 e 45 anos.

O desenvolvido das atividades seguiu o encaminhamento proposto no plano de atividades da ação, elaborados pelos pesquisadores: a) reconhecimento, pelos participantes da ação, da ferramenta mediadora do conhecimento, através da montagem, desmontagem e remontagem dos carrinhos robôs; b) introdução básica à programação simples dos carrinhos LEGO, o que capacitou aos participantes tentarem realizar a programação distinta de cada forma geométrica; c) do total de frequentes ao minicurso, ocorreu a partição em cinco grupos, sendo que cada um ficou responsável pela programação e implemento de uma forma geométrica específica (quadrado, retângulo, triângulo, círculo e losango). Um exemplo de programação desenvolvida, pelos grupos, é apresentado na Figura 2.

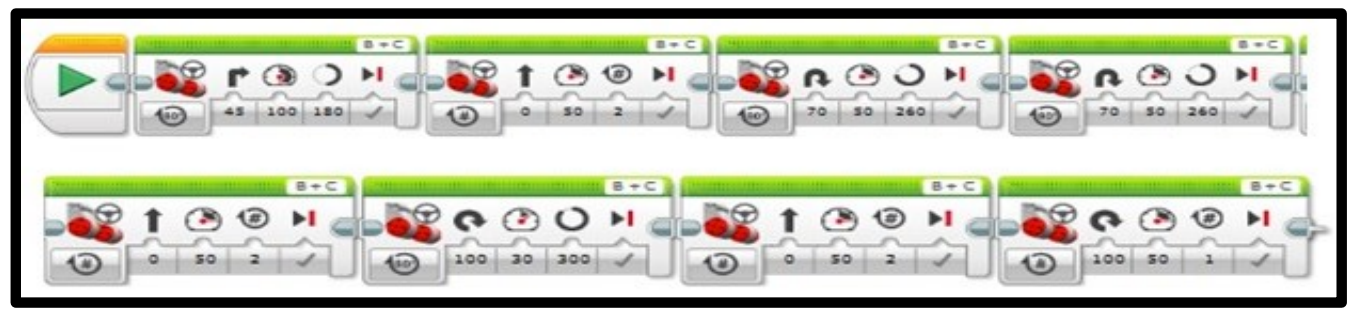

Figura 2 - Programação completa de um triângulo Fonte: Produção do autor (2019)

Ao final do minicurso, foi aplicado, com os participantes, um questionário referente ao mesmo, com o intuito de recuperar informações e impressões sobre a realização, aplicação e compartilhamento de conhecimentos acerca da robótica educacional, como metodologia de ensino, ferramenta mediadora do conhecimento, fonte de pesquisa, conhecimento agregado e estudos sobre educação e tecnologia. 


\section{ANÁLISE E RESULTADOS}

Ao final do minicurso foi aplicado um questionário para cada participante, objetivando verificar quais as opiniões, críticas e interesses deles após a execução das atividades propostas, de modo a promover discussões relacionadas ao que este estudo se propôs a realizar. Dentre as perguntas presentes no questionário, três delas se destacam como opiniões essenciais para alcançar os resultados esperados, para esta proposta de pesquisas explicitadas no quadro 1, a seguir.

\begin{tabular}{|c|l|}
\hline Pergunta 1 & $\begin{array}{l}\text { Você acredita que a Robótica pode ser utilizada como metodologia de ensino dentro e } \\
\text { fora da sala de aula nas diversas áreas de conhecimento? }\end{array}$ \\
\hline Pergunta 2 & $\begin{array}{l}\text { Você considera que é capaz de desenvolver a programação inicial dos robôs a partir } \\
\text { das orientações dadas durante o minicurso? }\end{array}$ \\
\hline Pergunta 3 & Quanto ao tema do minicurso, você considerou, de um modo geral, interessante? \\
\hline
\end{tabular}

Quadro 1 - Perguntas retiradas do questionário aplicado Fonte: Produção do autor (2019)

A partir das perguntas apresentadas no quadro 1, obteve-se então, os seguintes resultados. De acordo com o gráfico 1, todos os 24 participantes, acreditam que a Robótica Educacional pode atuar como ferramenta mediadora de conhecimento, reafirmando o que foi descrito por Araújo e Mafra, (2015), sobre o uso da Robótica Educacional como instrumento mediador de ensino, e reiterado por depoimentos dos participantes, tais como: A - "Muito proveitoso para nossa capacitação profissional.”; B - "Precisamos praticar mais"; C "Muito interessante, pois estava precisando aprender sobre esse lado da educação, e categoria de aprendizagem que se pode passar na sala de aula". 


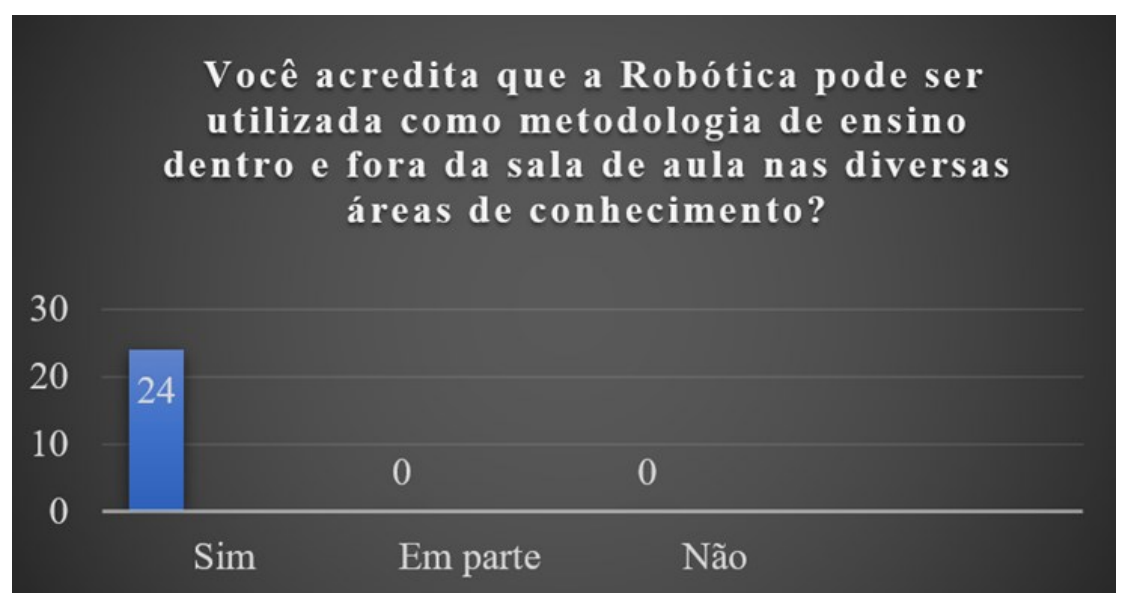

Gráfico 1 - RE como metodologia de ensino Fonte: Produção do autor (2019)

No estudo desenvolvido por Barbosa (2016), observou-se que "durante as oficinas de robótica na escola, vimos a necessidade de aprofundar a programação [...], percebemos que alguns alunos ainda estavam tendo dificuldade de entender a lógica de programação" (p. 235). Tal consideração, aproxima-se com as informações indicadas no gráfico 2, no qual se destaca que, 22 participantes afirmaram conseguir desenvolver uma programação inicial, enquanto 2 acreditam que conseguiriam "em parte", considerando o que foi ministrado durante o minicurso.

Assim, entendemos que - por mais que a ação desenvolvida tenha sido realizada em um curto espaço de tempo - com esta proposta, foi possível pensar uma oportunidade de discussão, a partir de um aprofundamento futuro sobre as questões aqui propostas, diretamente ligadas a robótica educacional.

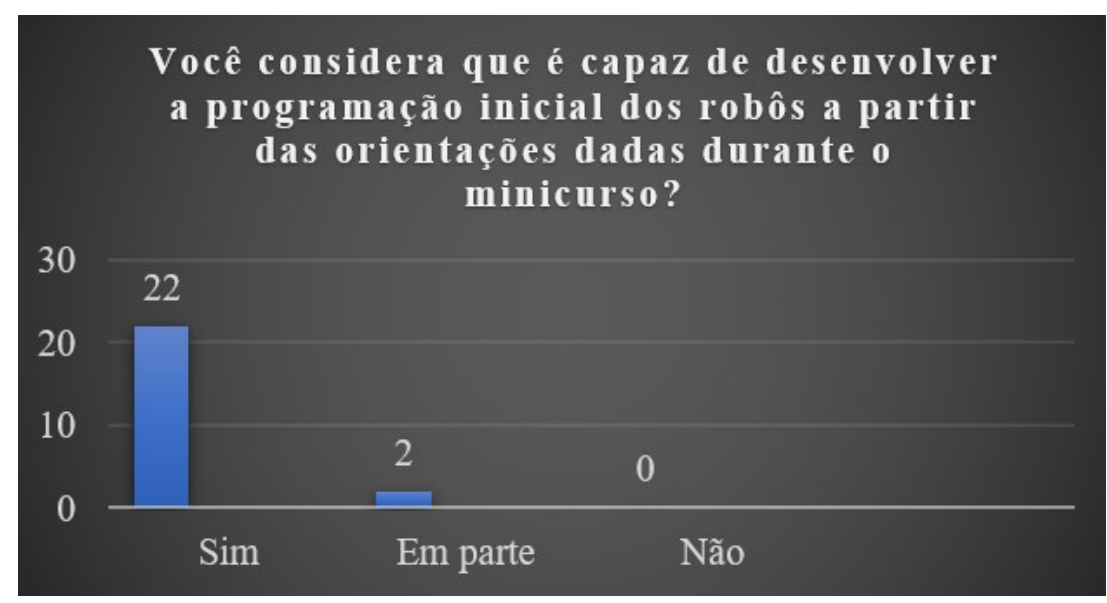

Gráfico 2 - Habilidades e conhecimentos tecnológicos Fonte: Produção do autor (2019) 
Ainda, ao observar o gráfico 2, é notória a opinião da grande maioria em relação à programação inicial, no qual 22 dos 24 participantes consideram-se capazes de desenvolver uma programação básica utilizando o programa EV3 com uma simples finalidade, seja para programar uma volta de $45^{\circ}$ ou uma forma geométrica mais simples, como o quadrado ou retângulo.

É importante salientar, que a programação apresentada durante o minicurso foi a mais simples possível, isto em virtude do pouco tempo disponibilizado para ele, no evento ao qual esteve integrado. Fato este, que inclusive, foi citado pelos participantes como: A - "Pouco tempo"; B - Tempo insuficiente”; C - "este curso deveria durar uma semana”; D - "O tempo de aplicação do curso pode ser a causa de ampliarlestender o conteúdo”.

Com efeito, o Gráfico 3 informa que 22 participantes consideram a Robótica Educacional como um assunto interessante, enquanto 2 acreditam que "em parte", nesta colocação.

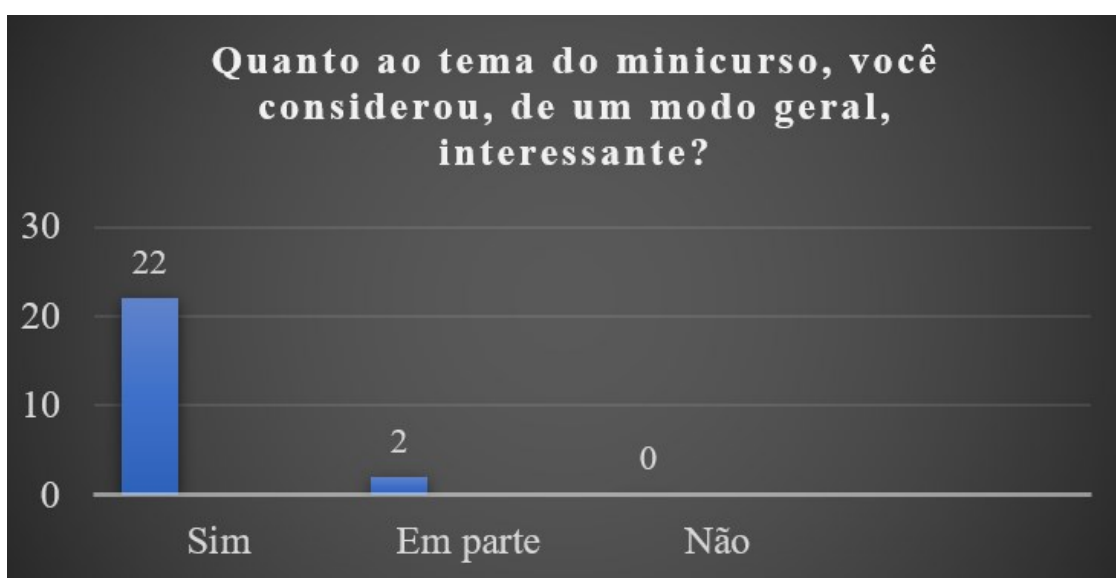

Gráfico 3 - Análise da $3^{\text {a }}$ Pergunta

Fonte: Produção do autor (2019)

Trazendo esse pensamento para a realidade da formação docente, do público-alvo envolvido na pesquisa, Cardoso (2016), afirma que "é mais importante entender a tecnologia como uma ferramenta pedagógica, apropriar-se dela de forma crítica e refletir sobre ela" ( $\mathrm{p}$. 67). Neste estudo a "tecnologia" aparece através do uso da robótica educacional, ressaltando ser necessário o interesse, estudo e aprofundamento pedagógico desta ferramenta mediadora para sua submissão no ambiente educacional.

Assim, ao analisar os gráficos, pode-se compreender que o nível de satisfação dos participantes foi considerável, o que apontou para um possível aprendizado. A partir destas prerrogativas, enfatiza-se que os objetivos propostos se aproximaram dos anseios e motivações 
dos participantes desta pesquisa, tendo em vista o bom desempenho das atividades propostas.

Além disso, atestamos que o contato, conhecimento e reconhecimento da ferramenta mediadora do conhecimento utilizada, proporcionou para a maioria dos participantes, o primeiro contato com a robótica em sua vida acadêmica.

Evidenciou-se também, com base em nossa experiência, o grande interesse dos participantes pelo tema "Robótica Educacional", o que surpreendeu os ministrantes, em virtude das atividades que foram planejadas, buscando a simplicidade como cúmplice, visto que já se presumia que, a maioria não possuísse contato anterior com a robótica. Em adição, se o público participante da experiência teve anteriormente esse contato, foi com a "robótica em si", ou seja, em relação ao "robô que executa atividades" e não como a "ferramenta mediadora de conhecimento", em vias de ser utilizada como um princípio educacional indutor, capaz de ser validada, em distintos ambientes de aprendizagem (GALVÃO, 2018; CEZAR, 2009).

Prensky (2001), expõe sobre a natureza "nativa digital" e "imigrante digital" da sociedade moderna, o que, de certa forma, culmina na aceitação de novas tecnologias em diversos âmbitos sociais, principalmente em meios que podem ser beneficiados por tais avanços, como a educação. Esta consideração, de acordo com Prensky, “abre portas” para a utilização de novas tecnologias e seus efeitos positivos, na sociedade. Desse modo, a RE ganha espaço como uma ferramenta mediadora, capaz de subsidiar a conexão entre os conhecimentos abordados pelo professor e a compreensão efetiva dos estudantes presentes em sala de aula, visualizando-a, como uma metodologia inovadora.

A afirmação de que a Robótica Educacional funcionaria como um "artefato mediador" (ARAÚJO, 2015), entendido como uma ferramenta mediadora sustentam-se nas opiniões colhidas pelo questionário, mais especificamente nas questões explicitadas nos gráficos 1, 2 e 3 acima e atestada pelos comentários a seguir: "Tudo foi muito bom por parte dos ministrantes."; "De maneira geral foi proveitoso."; “Tudo ótimo”.

A quase totalidade dos participantes (92\%) validou a iniciativa proposta, como uma ação importante, do ponto de vista tecnológico e educacional. A empregabilidade deste recurso tecnológico, como suporte de mediação do conteúdo matemático, em nosso caso, relacionada a geometria plana, através das formas geométricas, aponta para a sua validação como um princípio metodológico interessante e acessível ao aprendizado dos professores em formação, com vistas a agregar valor nesta enriquecedora experiência.

Ao final pôde-se concluir que a Matemática é um excelente exemplo de disciplina colaborativa, pois segundo Conceição, Jesus, Madruga (2018, p. 295) “há possibilidade de 
trabalhar a Matemática relacionada a ela mesma, com outras áreas de conhecimento, como também com o meio que a escola/aluno/professor estão inseridos." O que se evidenciou através das atividades com a ferramenta mediadora, garantindo uma aprendizagem colaborativa (ARAÚJO; MAFRA, 2015), mediada pelo apoio da tecnologia.

Em suma, acredita-se que foram alcançados bons resultados, contando com a colaboração dos participantes e o ensejo em confirmar que a RE como ferramenta mediadora de conhecimento, fornece um efeito positivo, do ponto de vista educacional, ao expandir possibilidades e horizontes relacionados as tecnologias. Deste modo, compreende-se que esta experiência foi de importante valor educacional, agregando informações necessárias e relevantes ao amadurecimento e conclusões inferidas aqui, com base na nossa experiência de pesquisa.

\section{CONSIDERAÇÕES}

Acreditamos que a RE é um forte avanço para a mediação da tecnologia dentro e fora da sala de aula, tendo em vista o crescimento das Novas Tecnologias presentes no ambiente escolar, tornando-se praticamente impossível ignorar os avanços tecnológicos que têm, diariamente, batido às portas da Educação. Desta forma, faz-se necessário receber novas tecnologias em sala de aula "de braços abertos", de modo que possibilite ao professor conforto e subsídio como mediadoras de conhecimento, transmitindo o conteúdo de maneira mais leve e interessante aos alunos, que hoje estão acostumados com lápis, papel, caneta e quadro.

É importante trazer o diferencial para a sala de aula, sem esquecer da principal funcionalidade destas tecnologias: proporcionar um melhor ritmo de aprendizado, assim como a quebra de rotina entre professor/aluno/tradicionalismo. Sem deixar de considerar pormenores, como dificuldades de adaptação, resistência ou desinteresse e a compreensão necessária de que para tudo tem uma primeira vez. Assim, entendemos ser importante persistir em tentativas que possam ser benéficas ao ambiente educacional.

Mediante o exposto, conclui-se que a RE tem potencial de atuação como uma ferramenta mediadora de conhecimento, responsável por abarcar grandes desenvolvimentos, como o envolvimento constante das novas tecnologias em suas diversas formas de aprimoramento, operando assim como um modelo alternativo para a metodologia educacional, contando principalmente com o apoio de profissionais, professores e alunos, engajados em trazer e fazer a diferença. 
No entanto, para um melhor empreendimento das tecnologias - neste estudo representada pela $\mathrm{RE}$ - o aperfeiçoamento e a qualificação de profisssionais, professores e técnicos no tocante ao desenvolvimento da educação, deve ser constante, haja vista, as crescentes e consistentes mudanças que estão acontecendo no âmbito social, o que por muitas vezes, atinge diretamente ambientes educacionais, trazendo tantos benefícios quanto malefícios. É necessário então, a correta preparação para lidar com os avanços e saber moldálos ao parâmetro educacional, papel este que requer o envolvimento e a participação direta de profissionais, neste caso, professores em formação, ou formados, como principais incentivadores do desenvolvimento da Educação e da Tecnologia Educacional.

Desafios como a falta de comunicação entre os membros das equipes, participação pouco efetiva de alguns integrantes ou a atenção excessiva ao celular, podem ser corriqueiramente vivenciados em sala de aulas normais, o que é esperado também, de certa forma, em momentos como estes, de minicursos e oficinas, nos quais são ofertados pequenos momentos de aprendizado, com trocas de experiências e vicissitudes.

Logo, torna-se nítido que todos devem ser capazes de ter acesso ao novo, ao melhor, ao aprimorado, seja isto um conteúdo a ser abordado no currículo escolar, um paradigma que está em desenvolvimento durante a capacitação dos profissionais especializados, ou uma ferramenta mediadora de conhecimento.

Conclui-se este estudo, afirmando a colaboração e inesquecível experiência proporcionada pelo descobrimento e abordagem da ferramenta mediadora de conhecimento, fundamental ao crescimento e desenvolvimento da educação, que agrega valor à formação inicial de professores e no aprendizado daqueles se se propõem a incorporar, criar e recriar novas metodologias. Estes profissionais que estarão, futuramente, gerenciando ambientes escolares, tais como as salas de aulas ou os laboratórios de aplicação certamente terão um acréscimo de conhecimento, relativo as tecnologias educacionais, mais especificamente à robótica educacional.

Em síntese, é fundamental buscar em primeiro lugar, a educação, como patrimônio de vida, percorrendo todos os degraus escolares, iniciando na educação infantil e estando em constante desenvolvimento até o ensino superior. Este fundamento, entendemos ter um papel indispensável, relativo aos conhecimentos propostos a sociedade e a educação da própria sociedade, refletindo assim, na própria concepção de humanidade. 


\section{REFERENCIAS}

ACCIOLI, R. M. Robótica e as Transformações Geométricas: um estudo exploratório com alunos do ensino fundamental. 2005. 223 f. Dissertação (Mestrado em Educação Matemática) - Curso de Mestrado em Educação Matemática, Pontifícia Universidade Católica de São Paulo, São Paulo, 2005. Disponível em: https://tede2.pucsp.br/handle/handle/11319 Acesso em 26 de jun. 2019.

ARAÚJO, C. A. P. As potencialidades da Robótica Educacional na Matemática básica sob as perspectivas da Teoria da Atividade. Dissertação (Mestrado em Educação) Programa de Pós-Graduação em Educação. Universidade Federal do Oeste do Pará, Santarém, 2015.

ARAÚJO, C. A. P.; MAFRA, J. R. S. Robótica e Educação: ensaios teóricos e práticas experimentais. 1 ed. Santarém: CRV, 2015. 111p.

AVELAR, M. S. de A.; SILVA, Y. R. de O. C. da.; NASCIMENTO, M. das G. C. de A. A formação docente e sua relação com a inserção profisssional: políticas docentes na rede municipal do Rio de Janeiro. Educação \& Formação. v. n.11, p. 179-196, 2019.

https://doi.org/10.25053/redufor.v4i11.1031

BARBOSA, F. C. et al. Mapeamento de Pesquisas sobre Robótica Educacional no Ensino Fundamental. Texto Livre: Linguagem e Tecnologia. v. 11, n. 3, p. 331-352, 2018. https://doi.org/10.17851/1983-3652.11.3.331-352

BARBOSA, F. C. Rede de aprendizagem em Robótica: uma perspectiva educativa de trabalho com jovens. Tese (Doutorado em Educação) - Programa de Pós-Graduação em Educação. Universidade Federal de Uberlândia, Uberlândia, 2016. Disponível em: https://repositorio.ufu.br/bitstream/123456789/17564/1/RedeAprendizagemRobotica.pdf Acesso em 26 de jun. 2019.

BARBOSA, F. M. D.; RODRIGUES, K. S.; AMORIM, E. M.; DA COSTA, N. P. O uso da robótica educacional como ferramenta mediadora no processo de ensino-aprendizagem da matemática no ensino fundamental em Lábrea-AM. In: ENCONTRO NACIONAL DE COMPUTAÇÃO DOS INSTITUTOS FEDERAIS (ENCOMPIF), 5. 2018, Natal. Anais do V Encontro Nacional de Computação dos Institutos Federais. Porto Alegre: Sociedade Brasileira de Computação, July 2018. Disponível em:

https://sol.sbc.org.br/index.php/encompif/article/view/3567/3526 Acesso em: 01 ago. 2020.

CARDOSO, A. C. S. Pro-Tecnologia: uma abordagem de formação inicial de professores para o uso das tecnologias digitais. Educação \& Formação. v. 1, n. 3, p. 50-70, 2016. http://dx.doi.org/10.25053/edufor.v1i3.1890

CÉSAR, D. R. Potencialidades e limites da Robótica Pedagógica Livre no Processo de (re)construção de conceitos científico-tecnológicos a partir do desenvolvimento de artefatos robóticos. Dissertação (Mestrado em Educação) - Programa de Pós-Graduação em Educação. Universidade Federal da Bahia, Salvador, 2009. Disponível em:

https://repositorio.ufba.br/ri/handle/ri/16044 Acesso em 25 de jul. 2019. 
CONCEIÇÃO, J. de S.; JESUS, G. B. de; MADRUGA, Z. E. de F. Contextualização no ensino de matemática: concepções de futuros professores. REAMEC - Rede Amazônica de Educação em Ciências e Matemática, v. 6, n. 2, p. 291-309, 2018. https://doi.org/10.26571/REAMEC.a2018.v6.n2.p291-309.i6941

FANTIN, M. Educação, Aprendizagem e Tecnologia na Pesquisa-formação. Educação \& Formação. v. 2, n. 3, p. 87-100, 2017. https://doi.org/10.25053/edufor.v2i6.2377

GALVÃO, A. P. Robótica Educacional e o Ensino de Matemática: Um experimento educacional em desenvolvimento no ensino fundamental. Dissertação (Mestrado em Educação) - Programa de Pós-Graduação em Educação. Universidade Federal do Oeste do Pará, Santarém, 2018. Disponível em: http://www.ufopa.edu.br/ppge/images/dissertacoes/turma_2016/angel_pena galvao.pdf Acesso em 04 de set. 2019.

GIL, A. C. Métodos e Técnicas de Pesquisa Social. 5 ed. São Paulo: Atlas, 1999.

JACON, L. da S. C.; OLIVEIRA, A. C. G. de; MARTINES, E. A. L. de M.; MELLO, I. C. de. Educação \& tecnologia: reflexões sobre a incorporação de tecnologias móveis na educação. REAMEC - Rede Amazônica de Educação em Ciências e Matemática, v. 1, n. 1, p. 88-101, 2013. https://doi.org/10.26571/2318-6674.a2013.v1.n1.p88-101.i5290

LAVILlE, C. DIONE J. A construção do saber. Porto Alegre: Artes Médicas, 1999.

MAY T. Pesquisa social: questões, métodos e processos. 3. Ed. Porto alegre: Artmed, 2004.

MINAYO, M. C. (org.). Pesquisa Social. Teoria, método e criatividade. 18 ed. Petrópolis: Vozes, 2001.

MORAES, M. C. Robótica Educacional: socializando e produzindo conhecimentos matemáticos. Dissertação (Mestrado em Educação) - Programa de Pós-Graduação em Educação em Ciências. Universidade Federal do Rio Grande, Rio Grande, 2010. Disponível em: http://repositorio.furg.br/handle/1/2864. Acesso em 25 de jul. 2019.

PRENSKY, M. Nativos Digitais, Imigrantes Digitais. Tradução de Roberta de Moraes Jesus de Souza. De On the Horizon (NCB University Press, Vol. 9 No. 5, Outubro 2001). Disponível em: http://www.colegiongeracao.com.br/novageracao/2 intencoes/nativos.pdf Acesso em: 24 jun. 2019.

SANTANA, M. do R. P. Em busca de outras Possibilidades Pedagógicas: "trabalhando" com Ciência e Matemática. Tese (Doutorado em Educação) - Programa de Pós-Graduação em Educação. Universidade Federal da Bahia, Salvador, 2009. Disponível em:

https://repositorio.ufba.br/ri/bitstream/ri/9184/1/Maria\%20do\%20Ros\%C3\%A1rio\%20P.\%20 de\%20Santana.pdf Acesso em 25 de jul. 2019.

SANTOS, B. M.; SILVA, H. E. da; ROSA, R. C. Relato de experiência: atividades lúdicas e experimentais para o ensino de ondas. REAMEC - Rede Amazônica de Educação em Ciências e Matemática, [v. 8, n. 2, p. 327-351, 2020. https://doi.org/10.26571/reamec.v8i2.9368 


\section{NOTAS}

\section{AGRADECIMENTOS}

À Universidade Federal do Oeste do Pará (UFOPA), ao Instituto de Ciências da Educação (ICED) e ao Curso de graduação em Licenciatura em Informática Educacional (LIE).

\section{FINANCIAMENTO}

Não houve financiamento.

\section{CONTRIBUIÇÕES DE AUTORIA}

Resumo/Abstract/Resumen: Zaira Karine Almeida Batalha Rodrigues, José Ricardo e Souza Mafra e Michel Marcos Abreu da Silva (revisor)

Introdução: José Ricardo e Souza Mafra

Referencial teórico: Zaira Karine Almeida Batalha Rodrigues

Análise de dados: José Ricardo e Souza Mafra

Discussão dos resultados: Zaira Karine Almeida Batalha Rodrigues

Conclusão e considerações finais: Zaira Karine Almeida Batalha Rodrigues e José Ricardo e Souza Mafra

Referências: Zaira Karine Almeida Batalha Rodrigues e José Ricardo e Souza Mafra

Revisão do manuscrito: Zaira Karine Almeida Batalha Rodrigues, José Ricardo e Souza Mafra e Michel Marcos Abreu da Silva (revisor)

Aprovação da versão final publicada: Zaira Karine Almeida Batalha Rodrigues e José Ricardo e Souza Mafra

\section{CONFLITOS DE INTERESSE}

Os autores declararam não haver nenhum conflito de interesse de ordem pessoal, comercial, acadêmico, político e financeiro referente a este manuscrito.

\section{DISPONIBILIDADE DE DADOS DE PESQUISA}

Os autores declaram que o conjunto de dados apresentados e que dá suporte aos resultados desta pesquisa é o que foi publicado no próprio artigo.

\section{CONSENTIMENTO DE USO DE IMAGEM}

Os autores declaram que os registros de imagens utilizadas no artigo foram devidamente autorizados. Os autores possuem os termos de autorização de imagens.

\section{APROVAÇÃO DE COMITÊ DE ÉTICA EM PESQUISA}

Declaramos, para os devidos fins, que os procedimentos e encaminhamentos relacionado aos requisitos éticos da pesquisa foram devidamente realizados e que os participantes manifestaram sua concordância na participação da mesma, conforme Termo de Consentimento Livre e Esclarecido (TCLE) assinados.

\section{COMO CITAR - ABNT}

RODRIGUES, Z. K. A. B.; MAFRA, J. R. S. Robótica Educacional como Ferramenta Mediadora: abordadando conceitos matemáticos na formação de professores. REAMEC - Rede Amazônica de Educação em Ciências e Matemática. Cuiabá, v. 9, n. 1, e21025, janeiro-abril, 2021. https://doi.org/10.26571/reamec.v9i1.11823

\section{COMO CITAR - APA}

Rodrigues, Z. K. A. B., \& Mafra, J. R. S. (2021). Robótica Educacional como Ferramenta Mediadora: abordadando conceitos matemáticos na formação de professores. REAMEC - Rede Amazônica de Educação em Ciências e Matemática, v. 9(1), e21025. https://doi.org/10.26571/reamec.v9i1.11823

\section{LICENÇA DE USO}

Licenciado sob a Licença Creative Commons Attribution-NonCommercial 4.0 International (CC BY-NC 4.0). Esta licença permite compartilhar, copiar, redistribuir o manuscrito em qualquer meio ou formato. Além disso, permite adaptar, remixar, transformar e construir sobre o material, desde que seja atribuído o devido crédito de autoria e publicação inicial neste periódico. 


\section{DIREITOS AUTORAIS}

Os direitos autorais são mantidos pelos autores, os quais concedem à Revista REAMEC - Rede Amazônica de Educação em Ciências e Matemática - os direitos exclusivos de primeira publicação. Os autores não serão remunerados pela publicação de trabalhos neste periódico. Os autores têm autorização para assumir contratos adicionais separadamente, para distribuição não exclusiva da versão do trabalho publicada neste periódico (ex.: publicar em repositório institucional, em site pessoal, publicar uma tradução, ou como capítulo de livro), com reconhecimento de autoria e publicação inicial neste periódico. Os editores da Revista têm o direito de proceder a ajustes textuais e de adequação às normas da publicação.

\section{PUBLISHER}

Universidade Federal de Mato Grosso. Programa de Pós-graduação em Educação em Ciências e Matemática (PPGECEM) da Rede Amazônica de Educação em Ciências e Matemática (REAMEC). Publicação no Portal de Periódicos UFMT. As ideias expressadas neste artigo são de responsabilidade de seus autores, não representando, necessariamente, a opinião dos editores ou da referida universidade.

\section{EDITOR}

Dailson Evangelista Costa (1) 0

\section{HISTÓRICO}

Submetido: 11 de fevereiro de 2021.

Aprovado: 03 de março de 2021.

Publicado: 01 de abril de 2021. 